Portland State University

PDXScholar

$1-2018$

\title{
How Do Stressed Workers Make Travel Mode Choices That Are Good For Their Health, Safety, and Productivity?
}

\author{
Liu-Qin Yang \\ Portland State University, lyang@pdx.edu \\ Brad Wipfli \\ OHSU-PSU School of Public Health \\ Lee Cyr \\ Portland State University \\ Kristina Marie Currans \\ Portland State University, curransk@gmail.com \\ Liming Wang \\ Portland State University
}

Follow this and additional works at: https://pdxscholar.library.pdx.edu/trec_reports

Part of the Transportation Commons, and the Urban Studies Commons Let us know how access to this document benefits you.

\section{Recommended Citation}

Yang, Liu-Qin, Liming Wang, Bradley Wipfli, Lee Cyr, and Kristina Currans. How do stressed workers make travel mode choices that are good for their health, safety, and productivity? NITC-SS-995. Portland, OR: Transportation Research and Education Center (TREC), 2018. https://doi.org/10.15760/trec.190

This Report is brought to you for free and open access. It has been accepted for inclusion in TREC Final Reports by an authorized administrator of PDXScholar. Please contact us if we can make this document more accessible: pdxscholar@pdx.edu. 


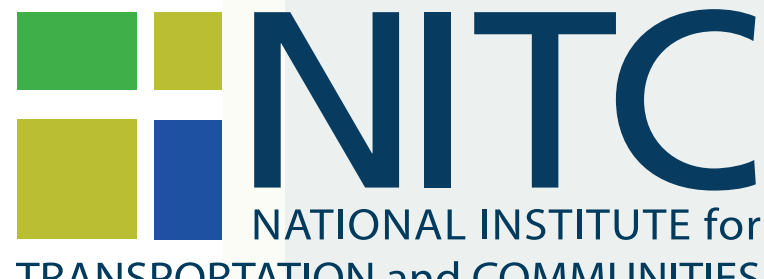

TRANSPORTATION and COMMUNITIES

FINAL REPORT

How Do Stressed Workers Make Travel Mode Choices That Are Good For Their Health, Safety, and Productivity?

NITC-SS-995 _ January 2018

NITC is a U.S. Department of Transportation

national university transportation center.

H:H TREC 



\title{
HOW DO STRESSED WORKERS MAKE TRAVEL MODE CHOICES THAT ARE GOOD FOR THEIR HEALTH, SAFETY, AND PRODUCTIVITY?
}

\author{
Final Report \\ NITC-SS-995 \\ by \\ PI: Liu-Qin Yang ${ }^{\mathrm{a}}$ \\ Co-PI: Brad Wipfli ${ }^{\mathrm{b}}$, and Liming Wang ${ }^{\mathrm{c}}$ \\ Lee Cyr \\ Kristina Currans ${ }^{\mathrm{d}}$ \\ Portland State University \\ ${ }^{a}$ College of Liberal Arts and Sciences: Department of Psychology \\ ${ }^{b}$ OHSU-PSU School of Public Health \\ ${ }^{\mathrm{C} C o l l e g e ~ o f ~ U r b a n ~ a n d ~ P u b l i c ~ A f f a i r s: ~ N o h a d ~ A . ~ T o u l a n ~ S c h o o l ~ o f ~ U r b a n ~ S t u d i e s ~ a n d ~ P l a n n i n g ~}$ \\ ${ }^{\mathrm{d}}$ Maseeh College of Engineering \\ for \\ National Institute for Transportation and Communities (NITC) \\ P.O. Box 751 \\ Portland, OR 97207
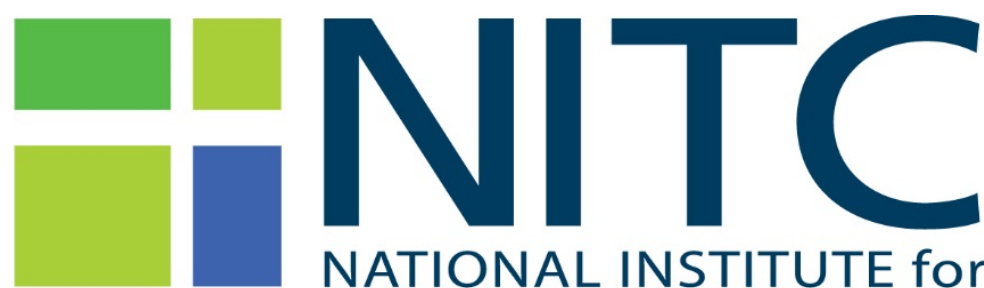 \\ TRANSPORTATION and COMMUNITIES
}

January 2018 


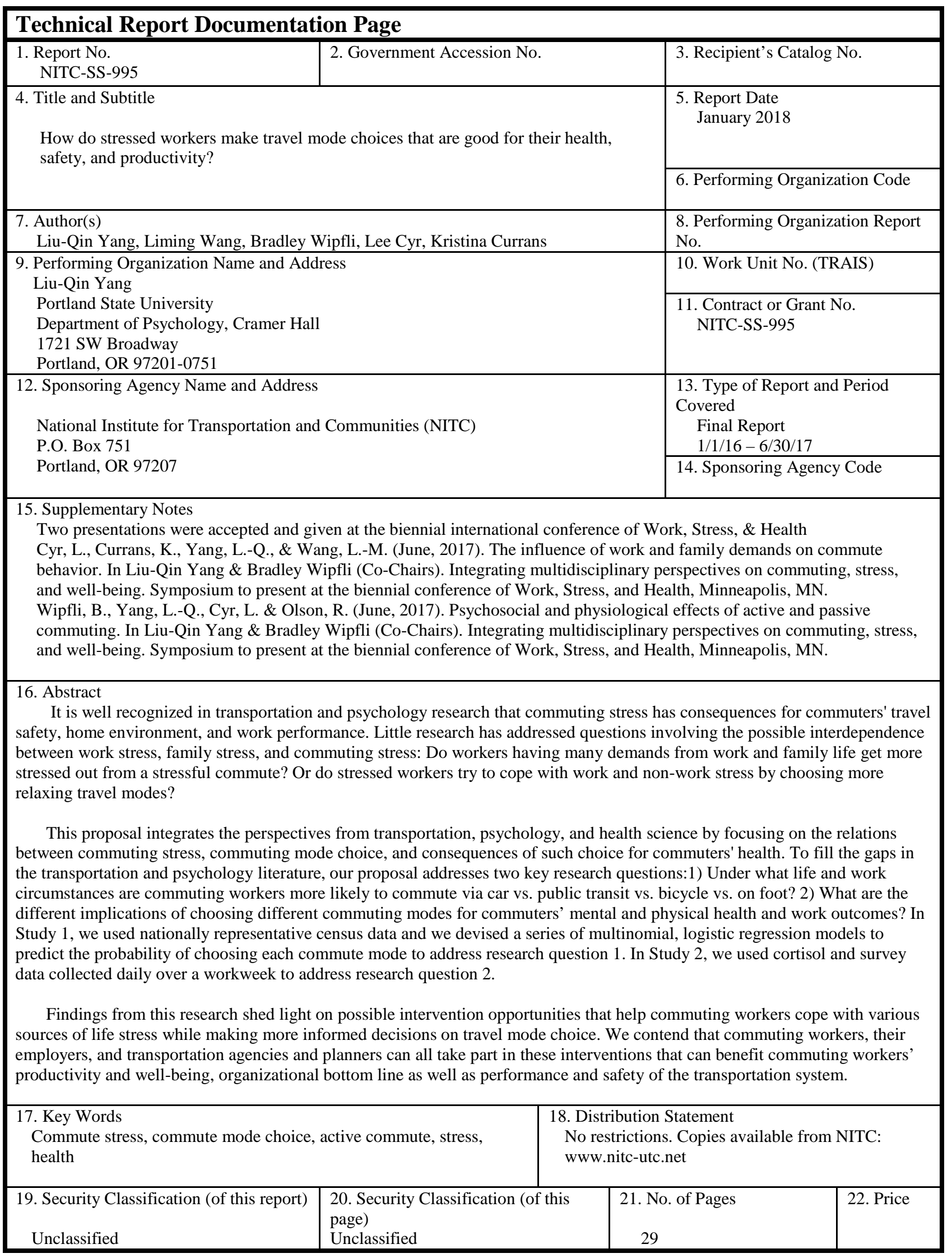




\section{ACKNOWLEDGEMENTS}

This project was funded by the National Institute for Transportation and Communities (NITC). We greatly appreciate NITC's support of our efforts to understand the integrative roles of work, non-work and/or family, and commuting on employee commute decisions, well-being, and work behavior. We also acknowledge the grant administrative staff (Amy Cissell, Eva-Maria Muecke and Lauren Scher) at Portland State University who managed administrative tasks, as well as the two research assistants, Kristina Currans and Lee Cyr, whose hard work and intellectual contributions made this work possible.

\section{DISCLAIMER}

The contents of this report reflect the views of the authors, who are solely responsible for the facts and the accuracy of the material and information presented herein. This document is disseminated under the sponsorship of the U.S. Department of Transportation University Transportation Centers Program in the interest of information exchange. The U.S. Government assumes no liability for the contents or use thereof. The contents do not necessarily reflect the official views of the U.S. Government. This report does not constitute a standard, specification, or regulation.

\section{RECOMMENDED CITATION}

Yang, Liu-Qin, Liming Wang, Bradley Wipfli, Lee Cyr, and Kristina Currans. How do stressed workers make travel mode choices that are good for their health, safety, and productivity?

NITC-SS-995. Portland, OR: Transportation Research and Education Center (TREC), 2018. 


\section{TABLE OF CONTENTS}

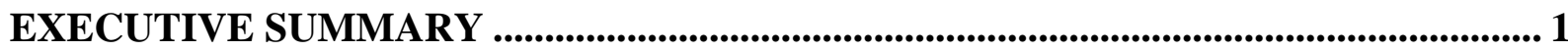

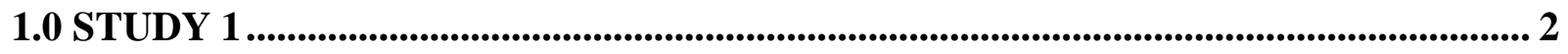

1.1 BACKGROUND 2

1.2 DATA 3

1.3 METHODS 5

1.3.1 DURATION OF MODE NOT TAKEN 6

$\begin{array}{lll}1.4 & \text { RESULTS } & 7\end{array}$

$\begin{array}{lll}1.5 & \text { SUPPLEMENTAL ANALYSES } & 12\end{array}$

$\begin{array}{ll}1.6 & 12\end{array}$

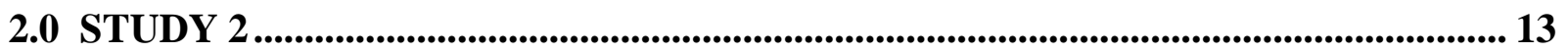

$\begin{array}{lll}2.1 & \text { BACKGROUND } & 13\end{array}$

$\begin{array}{ll}2.2 & \text { METHODS } \\ 2.3\end{array}$

$\begin{array}{lll}2.3 & \text { RESULTS } & 14\end{array}$

$\begin{array}{ll}2.4 & 19\end{array}$

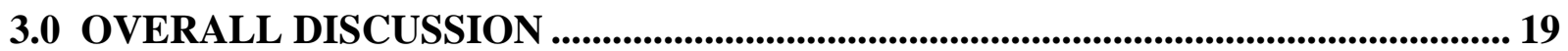

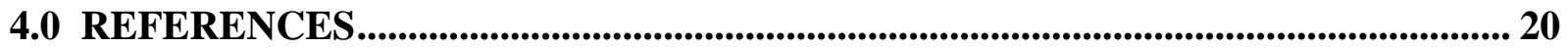

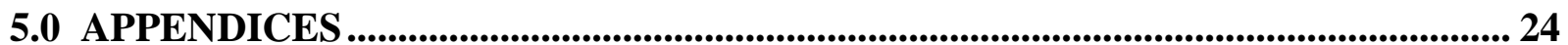

\section{List of Figures}

Figure 1. Overall conceptual model................................................ 3

Figure 2. Cross-level interaction of commute mode by stressful life events............. 18

\section{List of Tables}

Table 1. Study 1: MNL modeling components...................................... 4

Table 2. Study 1: MNL modeling equations and comparison tests....................... 7

Table 3: Study 1: Mode choice multinomial model results 9

Table 4. Study 2: Subgroup means for cortisol and focal variables................... 16

Table 5. Study 2: Multilevel descriptive statistics for cortisol and focal variables......... 17

Appendix 1. Study 1: Descriptive statistics for variables included in analyses........... 24

Appendix 2. Study 1: Subgroup (low SES) descriptive statistics for focal variables...... 25 


\section{EXECUTIVE SUMMARY}

Research on commute mode choice investigates the characteristics of commuting, demographics, psychosocial variables (e.g., family demands), and work that influence these choices. Similarly, research on physical activity, as it relates to active commute modes such as cycling and walking, study the benefits of these mode choices on individual well-being and work outcomes such as job performance. However, a relative dearth of focus exists in the literature that examines how characteristics of work, home, and commuting interact to explain commute mode choices, wellbeing, and work behavior. These characteristics may have independent, integrative, and/or additive effects on commute mode choice, well-being, and behavior at work and home. To address this gap in the literature, we conducted two studies.

In Study 1, we drew on commute mode-choice literature and psychological theory to define the pertinent work, home, and commute characteristics that influence mode choice. We conceptualized commute mode in three ways—automobile (driving, carpool, etc.); public transportation (bus, train, subway, etc); and active (walking or bicycling). Using nationally representative census data, we devised a series of multinomial, logistic regression models to predict the probability of choosing each commute mode. We controlled for the extraneous influence of factors not of interest such as whether these decisions occurred in a metropolitan area. Results showed that the best model(s) included work, home, and commute characteristics in additive and interactive fashion such that each domain exerted its own pertinent effect on mode choice and the interactions between these domains explained significant variance in the probability of choosing one commute mode or another. We discussed implications of our results for the transportation and psychology literature.

In Study 2, we drew on theory and empirical evidence relevant to physical activity on stress, coping, and work behavior. We dichotomized commute mode choice into two groups-nonactive commuters (drivers) and active commuters (cycling or walking that meets physical activity recommendations). Using cortisol and survey data collected daily over a workweek, we analyzed whether work and family stressors (sources of stress) and stress levels differed across mode choice on an intra- and inter-individual basis. We tested these relationships using multilevel modeling. Results showed some evidence that commute mode choice influences overall stress levels, work-to-family conflict, family-to-work conflict, job stress, and general life stress. We discussed implications of our results for the psychology, health science, and exercise science literature.

Overall, the analyses suggest that multiple life domains add to and interact to explain commute mode choice and that these choices indeed carry implications for commuters' work and wellbeing. The broader results and implications are discussed. 


\subsection{STUDY 1}

\subsection{BACKGROUND}

Commute modes_-automobile (Auto), public transportation (PT), cycling/walking (active commute or AC) — and their characteristics hold implications for employee well-being, such as perceived stress and salivary cortisol (Evans \& Wener, 2006); self-rated health and BMI (Berglund, Lytsy \& Westerling, 2016; Oliveira, Moura, Viana, Tigre \& Sampaio, 2015); chronic disease (Bopp, Kazczynski \& Campbell, 2013); and work outcomes, such as task performance (Evans \& Wener, 2006) and employee turnover (Faulk \& Hicks, 2016). Given the health and work outcomes of commute mode, a nuanced understanding of why people choose one or another seems imperative.

Research in transportation, public affairs, and urban planning largely investigates mode choice stemming from commute characteristics, and to a lesser extent work and family characteristics, and reveal practical ways employers might leverage less detrimental modes of commuting. Examples of commuting characteristics that influence various mode choices include distance (Heinen, Maat \& Van Wee, 2013); duration (Bopp et al., 2015; Kaczynski, Bopp \& Wittman, 2012); infrastructure (Broach, 2016; Chen, Gong \& Paaswell, 2008); and weather (Heinen, Maat \& Van Wee, 2011). Family demands include marital/cohabitation status and age/number of children (Bopp et al., 2015); life situation (i.e., newer vs. older family (Scheiner \& Holz-Rau, 2007)); and work demands including job changes (Clark, Chatterjee \& Melia, 2016), work hours (Bopp et al., 2015), and clothing requirements (Heinen et al., 2013). Whereas potentially helpful infrastructure investments in PT (Faulks \& Hicks, 2016) and AC accessibility (Broach, 2016) lie beyond employer control, employers increase the likelihood of AC by providing changing rooms, indoor bike-racks, and promoting pro-AC cultures and attitudes.

However, transportation studies of commute mode choice largely rely on models devised from decision making theories (e.g. Busemeyer \& Townsend, 1993; Mcfadden, 1974; Stern \& Richardson, 2005), ignore other psychological perspectives (for exceptions see Collins \& Chambers, 2005 and Scheiner \& Holz-Rau, 2007), and lack analyses that investigate how different domains (work, family, commute)uniquely influence and/or interact to explain them. Research in this regard could provide wider and deeper theoretical knowledge and practical directions to address health and work outcomes of commute modes. The present research addresses this gap by integrating transportation paradigms with psychological principles. The authors draw on activity-based models of mode choice (see Chu, Cheng \& Chen, 2012) and conservation of resources theory (COR; Hobfoll, 1989). That is, when commute, family, and work activities are more demanding (e.g. longer hours) people choose less demanding modes, and work or family demands compound the influence of commuting (Figure 1). Hence, from this point on, we refer to characteristics of these domains as demands. 


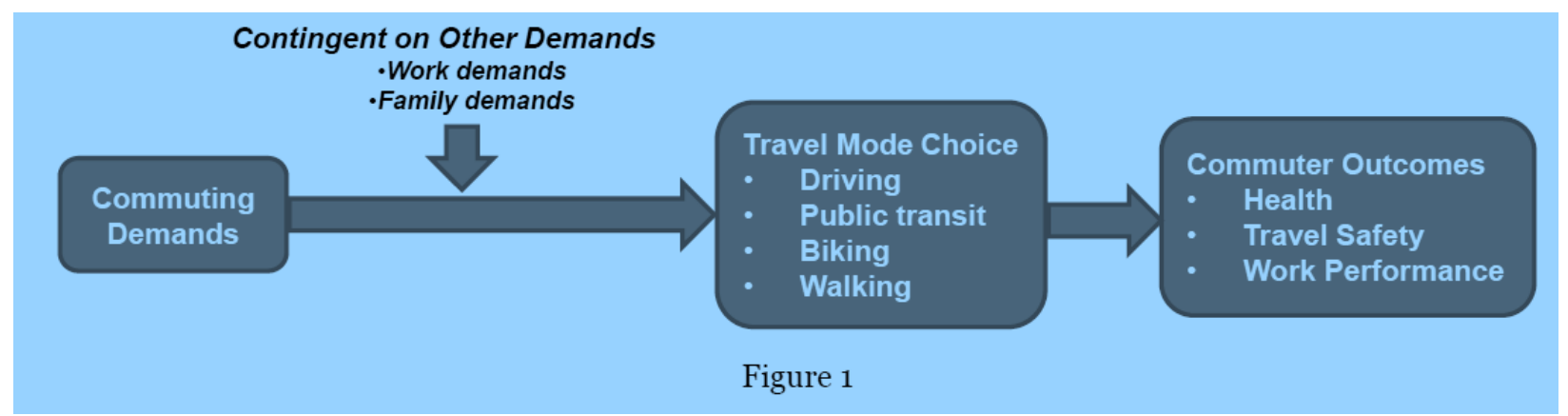

Figure 1. Overall conceptual model

\subsection{DATA}

Three years of a nationally representative survey-American Time-Use Survey (ATUS; Bureau of Labor Statistics, 2010, 2012, 2013) —were selected for the presence of focal variables and compiled $(n=2665)$. We defined individual mode choice as the dominant mode (longest duration) used for home-to-work commute and commute demand as total duration of the day's commute relative to the respondents' comparator estimates (intersection density, distance to transit stops, etc.; U.S. Census Bureau, 2014) for the modes not chosen. Variables are defined and described in Table 1.

\section{Table 1}

We chose these variables mainly based on the research from the transportation and psychology literature (e.g., Blanch \& Aluga, 2012; Gilboa et al., 2008; Hammer et al., 2005; Li et al., 2002; Novaco et al., 1990; Rimmele et al., 2007; Smith, 2013; Wener and Evans, 2011; Yang et al., 2012). For example, prior research in the transportation literature has identified objective (e.g., objective impedance like commuting distance and time) and subjective (e.g., feelings of irritation and frustration) stress factors during commutes that can explain travel mode choice better than factors like occupation and parking conditions (e.g., Li et al., 2002; Novaco et al., 1990; Wener and Evans, 2011). Based on the literature in work psychology, work demands (e.g., long work hours, work overload) have been shown to be a very common and consequential stressor around the globe (Yang et al., 2012). Variables describing the characteristics of the individual are divided into six components (i.e., W, F, D, Q, M, X) to simply the explanation of the methodology. This is referenced in Table 1 as well. 


\section{Table 1}

Study 1: MNL modeling components

\begin{tabular}{|c|c|c|}
\hline & Component & Variables \\
\hline \multirow[t]{5}{*}{$\begin{array}{l}\text { Characteristics } \\
\text { of the } \\
\text { individual, } i\end{array}$} & $\begin{array}{l}\mathbf{W}_{\mathrm{i}} \text { : respondent } \\
\text { work demands }^{1}\end{array}$ & $\begin{array}{l}\text { Duration of work (hours) } \\
\text { Change of duties (binary) } \\
\text { Work full/part time (binary) } \\
\text { One or multiple jobs (binary) }\end{array}$ \\
\hline & $\begin{array}{l}\text { Fi: respondent } \\
\text { family demands }{ }^{1}\end{array}$ & $\begin{array}{l}\text { Participant has a spouse (binary) } \\
\text { Participant's spouse is employed (binary) }{ }^{4} \\
\text { Number of children under } 18 \text { in the household } \\
\text { Duration of time spent caring for children (hours) } \\
\text { Respondent spent time caring for an adult (binary) } \\
\text { Average age of all of the household's children, whether or not they live } \\
\text { in the same household as the respondent } \\
\text { Duration of homecare (hours) }\end{array}$ \\
\hline & $\begin{array}{l}\text { Di: } \\
\text { sociodemographic } \\
\text { and economic } \\
\text { characteristics } \\
\text { describing either } \\
\text { the respondent or } \\
\text { the respondent's } \\
\text { household }\end{array}$ & $\begin{array}{l}\text { Gender of respondent (binary) } \\
\text { Household income }(\$ 10,000) \text { per household member } \\
\text { Age of respondent } \\
\text { Respondent is currently a student (binary) } \\
\text { Respondent has, in some part, a college education (binary) } \\
\text { Race of respondent, white (binary) } \\
\text { Race of respondent, black (binary) } \\
\text { Respondent is Hispanic (binary) }\end{array}$ \\
\hline & $\begin{array}{l}\mathbf{Q}_{\mathrm{i}}: \\
\text { diary day } \\
\text { information }\end{array}$ & $\begin{array}{l}\text { Year of diary (categorical: 2010, 2012, 2013) } \\
\text { Diary day on a weekend (binary) } \\
\text { Diary completed on a holiday (binary) } \\
\text { Diary completed during the winter months (November - February) }\end{array}$ \\
\hline & $\begin{array}{l}\mathbf{M}_{\mathrm{i}} \text { : locational } \\
\text { descriptors of the } \\
\text { home-location } \\
\text { context }\end{array}$ & $\begin{array}{l}\text { Home state (dummy variables) } \\
\text { Home is located in metropolitan area (binary) } \\
\text { Built environment and accessibility } 2,3 \\
\text { Average census block group (CBG) pedestrian intersection density } \\
\text { (intersections per square mile) } \\
\text { Average total CBG jobs within a 45-minute auto travel time (jobs) } \\
\text { Average total CBG jobs within a 45-minute transit travel time (jobs) } \\
\text { Average distance from population-weighted centroid of CBG to } \\
\text { nearest transit stop (meters) }\end{array}$ \\
\hline $\begin{array}{l}\text { Characteristics } \\
\text { of the } \\
\text { Alternatives, } t\end{array}$ & $\begin{array}{l}\mathbf{X}_{\mathbf{t}}: \text { commute } \\
\text { demands }\end{array}$ & Commute travel time (hours) ${ }^{5}$ \\
\hline
\end{tabular}

${ }^{1}$ Variables in matrices $\mathbf{W}$ and $\mathbf{F}$ describe activities on survey day, unless otherwise defined.

${ }^{2}$ Measures of the built environment are summarized from the Environmental Protection Agency's Smart Location Database (SLDB). Variables described are computed for the state of the respondent's home location, depending on whether the location was indicated as being inside and outside a metropolitan statistical area. Because variables in the SLDB are defined by the census block group geography, averaged measures reflect the average block group value observed in a given state and metro/non-metro designation.

${ }^{3}$ Measures were scaled.

${ }^{4}$ This variable only pertains to those who have a spouse; interpretation of this variable is that the employment of the spouse (binary) is interacted with whether the respondent has a spouse (binary). ${ }^{5}$ To estimate the duration of modes not taken, we calculated a look-up table of average travel times for commutes by car, transit, or active modes using the 2014 five-year American Community Survey (ACS)—specifically table B08134: Means of transportation to work by travel time to work. Frequency distributions for each state area at a county level were segmented into two categories: metropolitan statistical areas (MSAs) and not MSAs. Distributions were used to calculate average travel times for each mode. Values for duration, in hours, for the respondent's commute durations for the mode not taken were then pulled from these average values by state and MSA/non-MSA home location. 


\subsection{METHODS}

To examine these relationships, we use a multinomial logit (MNL) model that employs a utilitybased approach. A MNL approach allows the analyst to examine the trade-offs individuals make when evaluating multiple alternatives. In this analysis, we focus on the commute mode choice from home to work. In this method, the probability that an individual will elect to take a given mode alternative can be expressed as (Ben-Akiva \& Lerman, 1985):

$$
\text { Equation } 1 \quad P_{t}(i)=\operatorname{Pr}\left(U_{i t} \geq U_{j n}, \forall j \in C_{t}\right)=\frac{e^{v_{i t}}}{\sum_{j \in C_{t}} e^{v_{i t}}}
$$

Which is to say, the probability that individual, $i$, chooses alternative, $t$, can be expressed using the exponent of the systematic component of utility, $U_{i t}$, for the given alternative, $t$, divided by the sum of all alternatives, $j$, in the choice set, $C_{t}$. The choice set in this analysis includes three modes: (1) drive (alone or as a passenger), transit (all modes), and (3) active (bicycle and walking) modes. In this manuscript, we assume that every respondent has the full suite of alternatives available to them: drive, transit, or active modes. The utility, $U_{i t}$, can then be decomposed into two components, as described in Koppelman and Bhat (2006): (1) the systematic or observable portion of utility from alternative, t, for individual, i, and; (2) the portion of utility that is unknown to analysts or the error, $\varepsilon_{i t}$ :

Equation $2 \quad \mathrm{U}_{\mathrm{it}}=\mathrm{V}_{\mathrm{it}}+\varepsilon_{\mathrm{it}}$.

Furthermore, the systematic component, $\boldsymbol{V}_{\boldsymbol{i}}$, of utility can be decomposed into three portions associated with either: (1) characteristics of the individual, $\boldsymbol{D}_{\boldsymbol{i}}$; (2) attributes of the alternatives, $\boldsymbol{X}_{\boldsymbol{t}}$, and; (3) interactions between characteristics of the individual and attributes of the alternatives, $\boldsymbol{D}_{\boldsymbol{i}}$ and $\boldsymbol{X}_{\boldsymbol{t}}$. The specification of this deterministic component of utility can then be expressed as (Koppelman \& Bhat, 2006):

Equation $3 \quad \mathrm{~V}_{\mathrm{ti}}=\mathrm{V}\left(\mathbf{D}_{\mathbf{i}}\right)+\mathrm{V}\left(\mathbf{X}_{\mathbf{t}}\right)+\mathrm{V}\left(\mathbf{D}_{\mathbf{i}}, \mathbf{X}_{\mathbf{t}}\right)$

The variables defining the attributes of the alternatives, $\boldsymbol{X}_{\boldsymbol{t}}$, are limited. In this analysis, we consider the commute travel time burden (in minutes) of respondents recorded on the day of their survey. The variables defining the characteristics of the individual, $\boldsymbol{D}_{\boldsymbol{i}}$, can be segmented into four separate matrices, as described previously in Table 1.

Since we will be examining the ATUS, a national survey, we will explore the mode choice of individuals living in a broad range of contexts, both urban and rural, throughout the United States. Additionally, the ATUS masks the geographical location of households to the state level (with some indication of whether the household is located inside or outside a metropolitan statistical area), which constrains the ability to provide robust descriptions of the environment, including destination and transportation accessibilities or qualities. In other words, the masking of the geographical location produces a multilevel nesting of households within states. While we provide a few select state-level location variables (component $\mathbf{M}$, as described in Table 1), we control for the multilevel nature of this hierarchical structure by introducing dummy variables for each state location, including a dummy for each state-metro and each state-non-metro area type. 
Five models were estimated to examine each of the research questions; the systematic components, $\boldsymbol{V}$, of each model for alternative, $t$, and individual, $i$, were estimated using covariates for the respondent's sociodemographic, $\boldsymbol{D}_{\boldsymbol{i}}$, the respondent's home location, $\boldsymbol{M}_{\boldsymbol{i}}$, the timing of the diary day, $\boldsymbol{Q}_{\boldsymbol{i}}$ (each of which are described in Table 1). In Model 1 we introduce the alternative-specific commute duration, $\boldsymbol{X}_{\boldsymbol{t}}$, and compare against Model 0. Models 2 and 3 test the contribution of workloads, $\boldsymbol{W}_{\boldsymbol{i}}$, on mode choice alone and interacted with commute loads (respectively) and compared against Model 1. Models 4 and 5 test the contribution of family loads, $\boldsymbol{F}_{\boldsymbol{i}}$, on mode choice, first alone and then interacted with commute loads (respectively) and compared against Model 1. The mathematical specifications are identified in Table 2. A Loglikelihood Ratio Test is applied between each restricted and unrestricted model set to identify significance improvements (e.g., Model 1 versus 0; 2 versus 1) and are included in Table 3 in the following section.

Table 2 Study 1: MNL modeling equations and comparison tests

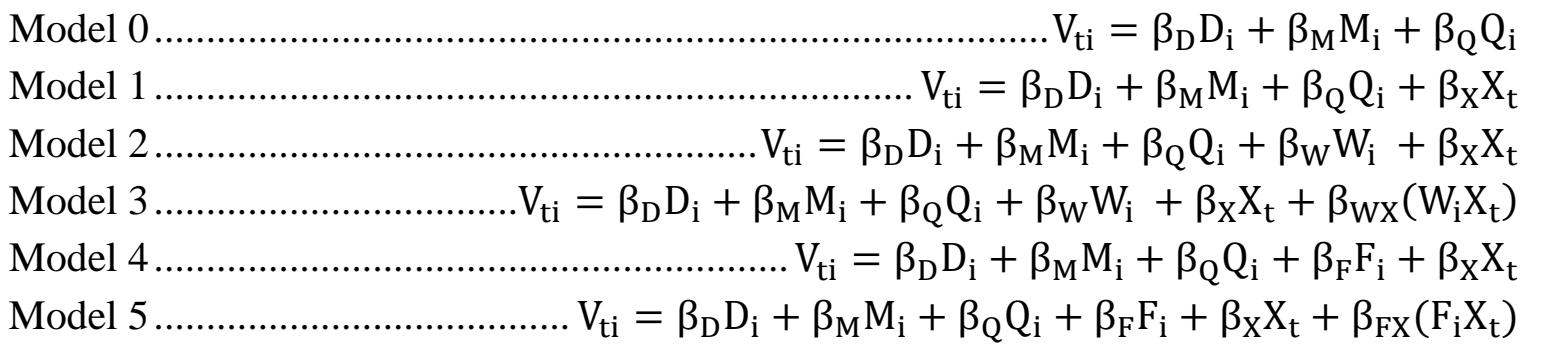

Note. $i=$ Characteristic of the individual, $W_{i}=$ Work demands, $F_{i}=$ Family demands, $X_{t}=$ Commute demands, $D_{i}=$ Sociodemographic controls, $M_{i}=$ Location descriptors, $Q_{i}=$ Diary day

\subsubsection{DURATION OF MODE NOT TAKEN}

While we selected the ATUS for this analysis because of the survey components capturing perceptions of wellness, this dataset is not without limitations. In particular, the most refined geographical scale provided for home locations are at a state level with a metropolitan statistical area (MSA) status or non-MSA status indicator. This reduces our ability to control for variations in urban context that may relate to the accessibility of specific mode choices, as well as the demand - in this case, duration — of the alternative mode not taken.

The ATUS data provide the duration for the mode used for travel. To estimate mode-choice models, it is necessary to have the information for duration for mode-not-chosen too, in addition to the availability of these non-chosen modes. However, given the limitation in ATUS data, we impute the duration of non-chosen modes using the National Household Travel Survey (NHTS) data. We summarize the NHTS commuting time by state, MSA status, and mode and look up the duration for non-chosen modes for each survey respondent in ATUS for the matched state, MSA status, and mode. This may not be the actual travel duration for the non-chosen modes for each survey respondent, but it may be the best information available given the limited information for survey respondents' home locations in the ATUS dataset. 
This approach of imputation for the duration of mode not taken is not without limitations. The ATUS was selected because of its inclusion of more rigorous measures of work and home characteristics and the additional data collected from a subset of individuals that provide additional information about the stress levels of that individual. The trade-off here is that the ATUS masks the individual's locational information by large aggregations. While a typical approach in travel behavior literature would be to control for urban form at a local level (Euclidean or network buffer around work and/or home locations), the use of ATUS does not provide this level of resolution. Instead, we control for these large regional differences using dummy variable. The high-level spatial aggregation of these variables may introduce additional error since the variation of urban form within each area (state non-MPO and state MPO) is large.

\subsection{RESULTS}

Full variable lists and descriptive statistics can be seen in Appendix 1. All five estimated models are shown in the following Table 3. For parsimony, we include only those variables indicated as being marginally significant $(\mathrm{p} \leq 0.20)$. In terms of model performance, using the LogLikelihood Ratio Tests we determine that Model 5 (Including Family interacted with Commute demand) explained significantly higher variation than Model 4 (without the interaction). Both Model 2 and Model 4 explain significantly higher variation than Model 1, suggesting the addition of work demands or family demands indicates a significant improvement in explaining mode choice. Lastly, the results did not indicate a significant improvement in the model when introducing work demands interacted with commute demands (Model 3), compared with work and commute demands as individual variables (Model 2).

Following, we will explore Model 5, which considers the relationship between family demands and commute demands, as individual and interacted variables. Because this study focuses on the compounded relationship between family demands and commute characteristics, we focus on these interacted variables. The results indicate a significant decrease in utility for taking transit with increases in commute duration and time spent in adult homecare, suggesting the compounded time requirements make transit less attractive for these households.

The number of children in the households is correlated with higher utility for taking transit, suggesting more children may increase the attractiveness of transit. Moreover, when households have older children, and the observed individual has a longer commute duration, the results indicate a positive and significant relationship with increased utility to drive. Households with childcare duties are also less likely to be attracted to transit (decreased utility for transit) when the commute time increases. Individuals with spouses are more likely to have higher utility in the transit mode choice - and even more in driving mode-if there is an increase in commute duration. However, if those spouses are employed and the commute duration increases, the results indicate a significant negative relationship with drive utility.

Several of these findings may be an artifact from using the ATUS data, which does not provide information about vehicle ownership, which is often correlated with income, life stage, household size and --another limitation of this data. The authors urge caution in interpreting the effect size of these variables - specifically due to the limitations of ATUS as used for modechoice models as mentioned previously (e.g., aggregation of spatial locations). However, the indication of significance in these models (both for individual variables and in the model 
building process) — particularly where family demands are interacted with commute demandssuggest that the decision of commute mode is a complex one. The factors that influence the attractiveness of each mode vary and do not appear to be consistent across modes; for example, commute duration interacted with number of kids is significantly related to the increase in transit utility, but the average age of the kids interacted with commute duration is significantly related to an increase in drive utility. Original data collection oriented at addressing these differential findings - and other limitations of this study — would be necessary to address these questions 
Table 3.

Mode choice multinomial model results

\begin{tabular}{|c|c|c|c|c|c|c|c|c|c|c|c|c|}
\hline \multirow[b]{2}{*}{ Log-Likelihood (Null) } & \multicolumn{2}{|c|}{ Model 0} & \multicolumn{2}{|c|}{ Model 1} & \multicolumn{2}{|c|}{ Model 2} & \multicolumn{2}{|c|}{ Model 3} & \multicolumn{2}{|c|}{ Model 4} & \multicolumn{2}{|c|}{ Model 5} \\
\hline & & -624.07 & & -624.07 & & -624.07 & & -624.07 & & -624.07 & & -624.07 \\
\hline Log-Likelihood (Beta) & & -481.42 & & -407.8 & & -397.42 & & -394.78 & & -387.54 & & -372.51 \\
\hline Rho $^{2}$ & & 0.23 & & 0.35 & & 0.36 & & 0.37 & & 0.38 & & 0.4 \\
\hline Rho $^{2}$ Adjusted & & 0.01 & & 0.12 & & 0.13 & & 0.11 & & 0.13 & & 0.13 \\
\hline McFadden's $\mathrm{R}^{2}$ & & 0.23 & & 0.35 & & 0.36 & & 0.37 & & 0.38 & & 0.4 \\
\hline \multirow[t]{3}{*}{ Responses (N) } & & 2665 & & 2665 & & 2665 & & 2665 & & 2665 & & 2665 \\
\hline & \multicolumn{12}{|c|}{\begin{tabular}{l|l} 
Estimate & t-statistic
\end{tabular}} \\
\hline & -3.49 & $-2.18 *$ & -3.14 & -1.91 & --- & --- & -2.76 & -1.43 & -2.62 & -1.56 & -3.47 & $-2.02 *$ \\
\hline \multicolumn{13}{|l|}{ D: Person } \\
\hline \multicolumn{13}{|l|}{ Gender } \\
\hline Active & -0.48 & -1.84 & -0.6 & $-2.22 *$ & -0.75 & $-2.68 * *$ & -0.79 & $-2.76 * *$ & -0.81 & $-2.75^{* *}$ & -0.81 & $-2.72 * *$ \\
\hline Transit & -0.7 & $-2.33^{*}$ & -0.65 & -1.94 & -0.65 & -1.87 & -0.7 & $-1.98 *$ & -0.54 & -1.51 & -0.55 & -1.51 \\
\hline Income: Active & --- & --- & --- & --- & --- & --- & --- & --- & -0.1 & -1.61 & -0.11 & -1.67 \\
\hline \multicolumn{13}{|l|}{ Age } \\
\hline Active & --- & --- & --- & --- & --- & --- & --- & --- & --- & --- & --- & --- \\
\hline Transit & -0.04 & $-3.4 * *$ & -0.04 & $-2.84 * *$ & -0.04 & $-3.03 * *$ & -0.04 & $-2.97 * *$ & -0.03 & -1.75 & -0.03 & -1.85 \\
\hline Student: Transit & -1.62 & -1.55 & --- & --- & -1.54 & -1.37 & -1.51 & -1.34 & -1.53 & -1.4 & -1.58 & -1.45 \\
\hline Highschool: Active & -0.57 & $-2.05^{*}$ & -0.53 & -1.81 & -0.54 & -1.8 & -0.54 & -1.8 & -0.41 & -1.35 & --- & --- \\
\hline \multicolumn{13}{|l|}{ Race/Ethnicity } \\
\hline White: Transit & -0.69 & -1.34 & -0.96 & -1.65 & -1.05 & -1.77 & -1.16 & -1.95 & -1.23 & $-2.04 *$ & -1.37 & $-2.08 *$ \\
\hline Black: Transit & 1 & 1.78 & --- & --- & --- & --- & --- & --- & --- & --- & --- & --- \\
\hline Hispanic: Transit & 1.17 & $2.81 * *$ & 1.36 & $2.9 * *$ & 1.39 & $2.85 * *$ & 1.47 & $2.97 * *$ & 1.2 & $2.44 *$ & 1.18 & $2.28 *$ \\
\hline \multicolumn{13}{|l|}{ M: Location } \\
\hline \multicolumn{13}{|l|}{ Destination Accessibility } \\
\hline Transit & --- & --- & --- & --- & --- & --- & --- & --- & --- & --- & 5.15 & 1.32 \\
\hline Active & -0.63 & -1.3 & -0.65 & -1.3 & -0.68 & -1.38 & -0.66 & -1.32 & --- & --- & --- & --- \\
\hline \multicolumn{13}{|l|}{ Intersection Density } \\
\hline Transit & --- & --- & --- & --- & --- & --- & --- & --- & --- & --- & 11.98 & 1.47 \\
\hline $\begin{array}{l}\text { Note: } * * * \text { p-value }<0.0 \\
\text { variable is not signfician } \\
\text { Table } 3 . \text { (continued) }\end{array}$ & alue $<$ & $01 ; * \mathrm{p}-$ & & & & & & & & & $<0.2)$ & \\
\hline
\end{tabular}




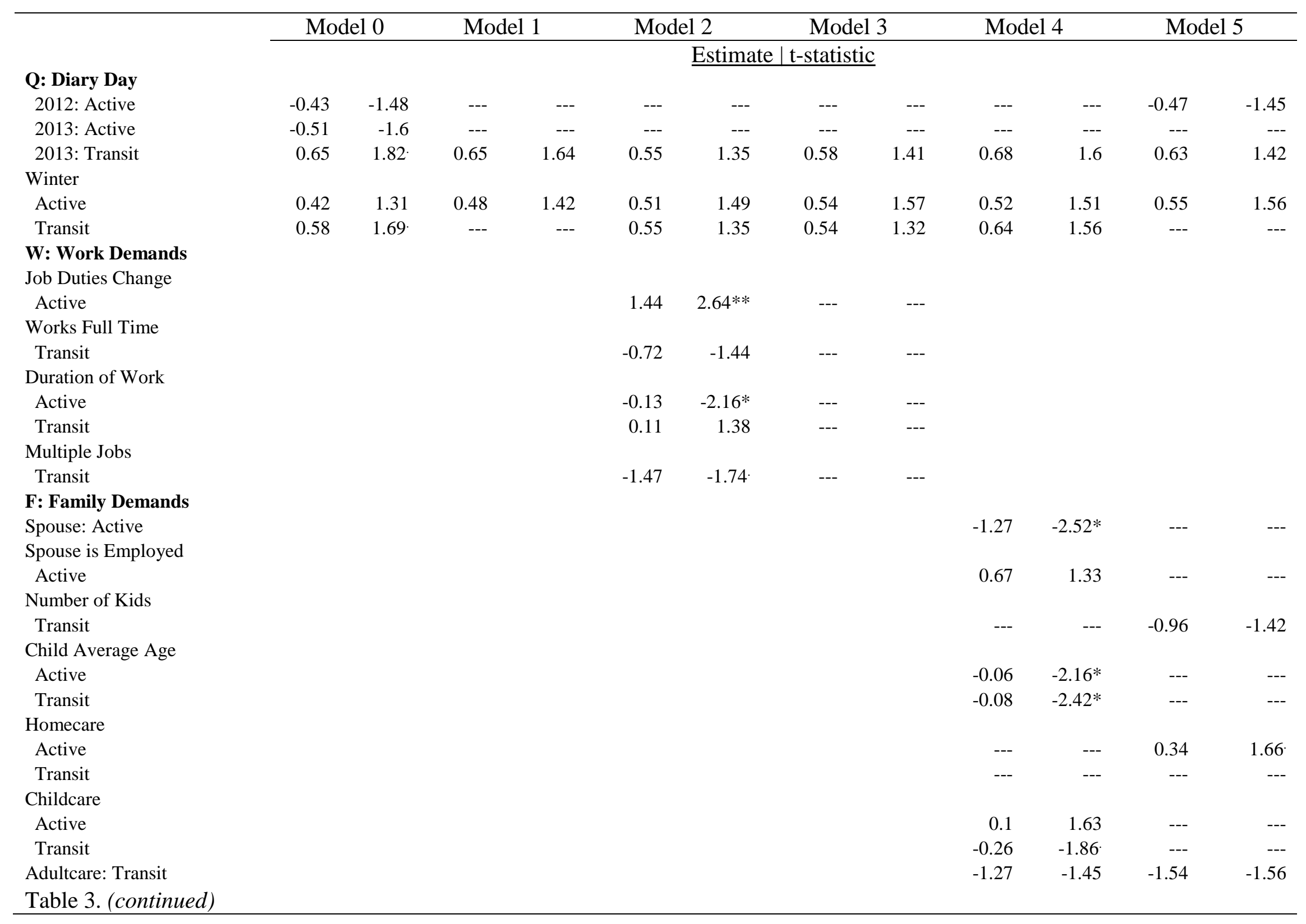




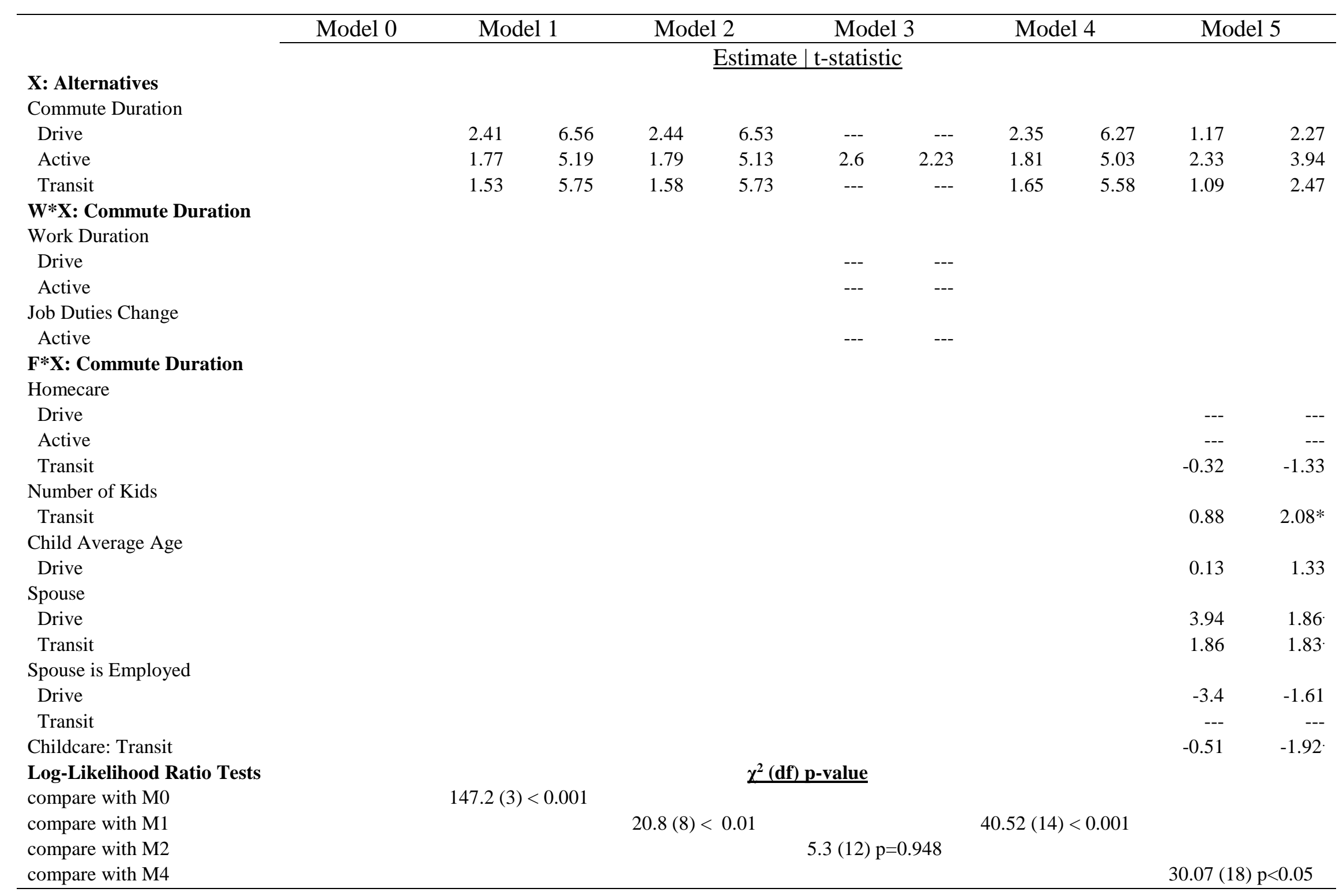




\subsection{SUPPLEMENTAL ANALYSES}

As part of our original design, a secondary analysis was prepared to compare the hypothesized relationships from the general population to a specific population of those having low social economic status (SES). To define this population U.S. Department of Health \& Human Services (2017) concepts were used to specify any individual having an income below approximately $\$ 12,000$ dollars per year or any household having less than approximately $\$ 4,200$ per additional household member. This resulted in a sample that was too small to run our MNL models for comparison $(n=191)$. However, a set of descriptive statistics and correlations were run for comparison purposes (Appendix 2). Notably, the market share for Auto, Transit, and Active are considerably different at .95, .02, .03, in general, compared to .84, .09, .06, for those below the poverty line, respectively. In addition, the correlations between race and mode choice increased markedly for those below the poverty line such that Caucasian was positively associated to Auto and negatively associated to Transit and Active $(r=.20,-.14,-.13)$, and Black showed an opposite pattern $(r=-.22, .16, .14)$. This was a steep increase compared to the general population ( $\mathrm{r}=.06,-.09, .01$, n.s. and $-.07, .09, .00$, n.s.). Full descriptive results are shown in Appendix 2.

\subsection{CONCLUSIONS AND DISCUSSION}

Although not all models isolating individual components of interest showed incremental validity, our results did show some promising findings that are consistent with our theoretical propositions. For example, Model 2 had incremental validity than Model 1, suggesting that it is important to take into account work characteristics in addition to commute characteristics in predicting mode choice. As another example, Model 5 had incremental validity than Model 4, suggesting that the joint (interaction) effect of family and commute characteristics can be meaningful in increasing the validity of the mode choice model. The fact that an exhaustive model including work, family, commute demands, and their interactions accounted for the most variance highlights the important interplay among these components when predicting commute decisions. Furthermore, the results are limited by the number of location controls and imprecise comparator estimates. However, the results carry practical implications. Employer efforts to provide and promote active-commute friendly environments might benefit from considering family/work by commute interactions; including family and/or work considerations in activecommute promotion signs, for instance, may prove useful. Future research should consider more refined comparator estimates of mode-not-taken in a multilevel model to improve precision and power as well as seek to assess implications of various demands directly and experimentally. 


\subsection{STUDY 2}

\subsection{BACKGROUND}

Despite the significant benefits of exercise, less than half of the U.S. adult population meets the Center for Disease Control's aerobic Physical Activity Guidelines (CDC, 2011a). Lack of time is the most common reason given for not exercising. Active commuting (e.g., walking, bicycling) is a potential solution to this dilemma, because people can meet the aerobic activity recommendations during the time that they would normally be sedentary. Some empirical evidence suggests that active commuting may also improve well-being, and may have numerous potential physical health benefits (e.g., Karasek \& Krausz, 1990; Robinson, 1991; Koslowosky et al., 1993; Morris et al., 1990). The timing of active commuting may provide additional physical and mental health benefits by buffering against the harmful effects of family-to-work conflict (FWC; when family life influences work activity), job stress, and work-to-family conflict (WFC; when work life influences family activity). However, active commuting rates are relatively low (Hu \& Reuscher, 2004), and the potential benefits of active commuting have not been fully explored. For example, exercise is related to improvements in cognitive functioning, mood, and attention (Kouvonen et al., 2005; Dunn et al., 2005), and the timing of active commuting may therefore increase work engagement or facilitate recovery from work in the evening. Active commuting also has the potential to mediate or moderate the relationship between stressors and strain. The purpose of this study is to evaluate the effects of active commuting on psychosocial outcomes at work and at home, along with daily cortisol profiles.

We hypothesized that active commuters have lower FWC, WFC, job stress, and general stress than non-active commuters. We hypothesize that active and non-active commuters have different cortisol profiles. We also explored the potential role of active commuting in helping commuters to better manage their daily stress, so that active commuters might have weaker daily reactions to certain daily stressful life or work conditions (e.g., stressful life events), as compared to nonactive commuters.

\subsection{METHODS}

We recruited participants from a large organization in the Western United States. Participants were required to have two-plus years of job tenure at the organization, work 30+ hours per week (day shifts only), and either be in a live-in relationship or have dependent children at home. Participants were also required to consistently either drive, walk, or bike to work, and non-active commuters were required to exercise for 30 minutes or more on at least four days per week, which would allow us to examine if the impact of active commuting differs from that of regular exercise. The final sample $(n=60)$ included $n=29$ active commuters (bikers and walkers) and $n$ = 31 non-active commuters (drivers). Participants completed informed consent and a baseline survey at initial recruitment. Each participant then completed two online daily surveys each workday for one week (five consecutive workdays). The first survey was completed in the morning at work, and included questions about the person's commute and psychological measures (see Table 1 below for a complete list of measures included in each survey). The second online survey was completed in the evening at home. Researchers emailed survey links 
to participants, and either sent a text message or an email to remind participants to take each daily survey. In addition to survey measures, we collected saliva samples from participants to assess daily cortisol profiles. We provided each participant with instructions and a kit for collecting saliva samples. Participants provided saliva five times a day for five workdays: before rising from bed in the morning, 30 minutes after rising from bed, before lunch, before dinner, and before bed. Participants received \$50 and entry into a drawing for supplemental compensation for completing all cortisol samples and daily surveys.

The dataset includes both baseline variables and nested, daily-diary variables, and we used a combination of correlations and multilevel modeling to examine these hypotheses in Mplus 5.21 and SPSS24.0. The variables about individual characteristics were defined at Level 2 or between-person level while the daily state variables were defined as Level 1. For instance, a person's commute mode (e.g., active) represents a Level 2 variable, and a person's cortisol activities or survey responses for the day (e.g., work-to-family conflict) represent Level 1. This design allowed us to examine the between- and within-person effects of our proposed relationships. For moderation analyses, Level 1 person-mean centering was used to create interaction terms.

We tested for between groups (active vs. non-active) differences on all baseline measures and demographic variables. The only measure or demographic that approached statistical significance was age, with active commuters (mean age $=35.9$ ) tending to be younger than nonactive commuters (mean age $=40.6$ ) at a statistical level of approaching marginal significance ( $\mathrm{p}$ $=.11$ ). While controlling for too many variables would substantially reduce statistical power with a sample of $n=60$, each model included controls for covariates that have potential impacts on outcome variables: age, gender, marital status, baseline physical activity levels, baseline average commuting time, whether or not the participant was taking blood pressure medication, and baseline life events stress.

\subsection{RESULTS}

Participant data collection compliance was very good. We received 1485 of the expected 1500 cortisol samples (99\%). Survey response rates were similarly high. Participants completed 294 of the 300 expected daily surveys at work (98\%), and 289 of the 300 expected daily surveys at home (96.3\%).

Compared to non-active commuters, active commuters had significantly lower person-level FWC ( $(=-0.27, p<.05)$. Consistent with the results in Table 4, we found that active commuting was beneficial to the management of person-level overall job stress and mean FWC scores from daily surveys at a marginally significant level ( $(=-0.20$ and $-.23, p=.10$ and .09 , respectively), with a similar set of covariates controlled. There was a significant correlation between person-level WFC and mean daily cortisol volume (area under the curve; $r=-.29, p<$ .05), which means that average daily cortisol awakening response was lower when WFC was higher. There was also a significant correlation between mean volumetric cortisol awakening response and person-level general life stress ( $r=.28, p<.05$; correlation matrix, Table 5), which means that general stress increased as a person's average daily cortisol volume increased (i.e., an individual generally has more difficulty regulating cortisol to a lower level toward the end of the workday). We did not find support for the remaining hypotheses. 
Regarding the exploratory analyses, the cross-level moderation was significant for the relationship between stressful life events and WFC. Specifically, there was a buffering effect of being in the active group such that more stressful events lead to a decrease in WFC while the opposite was true of those in the non-active group. Simple slopes analysis is shown in Figure 2.

Table 4

Study 2: Subgroup means for cortisol and focal variables

\begin{tabular}{|c|c|c|c|c|c|c|}
\hline \multirow[b]{2}{*}{ Variables } & \multicolumn{3}{|c|}{ Active } & \multicolumn{3}{|c|}{ Non-active } \\
\hline & $n$ & Mean & $S D$ & $n$ & Mean & $S D$ \\
\hline \multicolumn{7}{|l|}{ Baseline } \\
\hline Work to family ${ }^{\dagger}$ & 29 & 2.44 & 0.97 & 31 & 2.55 & 0.95 \\
\hline Family to work* & 29 & 1.86 & 0.68 & 31 & 2.25 & 0.98 \\
\hline General stress & 29 & 9.00 & 3.01 & 31 & 9.81 & 3.43 \\
\hline Job stress $^{\dagger}$ & 29 & 3.21 & 0.74 & 31 & 3.52 & 0.80 \\
\hline \multicolumn{7}{|l|}{ Daily } \\
\hline Work to family & 29 & 2.27 & 0.77 & 31 & 2.19 & 0.92 \\
\hline Family to work & 29 & 1.73 & 0.68 & 31 & 1.94 & 0.74 \\
\hline General stress & 29 & 2.50 & 0.70 & 31 & 2.58 & 0.78 \\
\hline Job stress & 29 & 10.41 & 2.70 & 31 & 10.00 & 3.24 \\
\hline $\mathrm{AUC}_{\mathrm{g}}$ & 27 & 335.68 & 97.90 & 30 & 363.53 & 136.86 \\
\hline $\mathrm{AUC}_{1} *$ & 27 & 49.94 & 54.04 & 30 & 65.23 & 96.00 \\
\hline
\end{tabular}

Note. AUC variables are measured in $\mathrm{nmol} / \mathrm{L}$ per minute. $\mathrm{AUC}_{\mathrm{g}}=$ Area under the curve with respect to total cortisol output, $\mathrm{AUC}_{1}=$ Area under the curve with respect to cortisol awakening response.

$\dagger=\mathrm{p}<.10$

$*=\mathrm{p}<.05$ 
Table 5

Study 2: Multilevel descriptive statistics for cortisol and focal variables

\begin{tabular}{|c|c|c|c|c|c|c|c|c|c|c|c|c|c|}
\hline & Mean & $S D$ & 1 & 2 & 3 & 4 & 5 & 6 & 7 & 8 & 9 & 10 & 11 \\
\hline \multicolumn{14}{|l|}{ Baseline Variables } \\
\hline 1. Active & 0.48 & 0.50 & - & & & & & & & & & & \\
\hline 2. Work to family & 2.50 & 0.95 & -.06 & - & & & & & & & & & \\
\hline 3. Family to work & 2.05 & 0.86 & -.23 & $.375^{* *}$ & - & & & & & & & & \\
\hline 4. General stress & 9.42 & 3.23 & -.13 & .126 & .061 & - & & & & & & & \\
\hline 5. Job stress & 3.37 & 0.78 & -.20 & $.490^{* *}$ & .191 & $.380^{* *}$ & - & & & & & & \\
\hline \multicolumn{14}{|l|}{ Daily Variables } \\
\hline 6. Work to family & 2.23 & 0.85 & .05 & $.670^{* *}$ & $.390^{* *}$ & .180 & $.403^{* *}$ & - & -.114 & -.109 & -.124 & -.009 & -.031 \\
\hline 7. Family to work & 1.84 & 0.71 & -.15 & $.435^{* *}$ & $.611^{* *}$ & .096 & $.335^{* *}$ & $.630^{* *}$ & - & .009 & .103 & .008 & .029 \\
\hline 8. General stress & 10.20 & 2.97 & -.05 & $.381^{* *}$ & $.342^{* *}$ & .212 & $.704^{* *}$ & $.439^{* *}$ & $.441^{* *}$ & - & .029 & -.080 & -.061 \\
\hline 9. Job stress & 2.54 & 0.74 & .07 & $.340^{* *}$ & $.275^{*}$ & $.546^{* *}$ & $.456^{* *}$ & $.526^{* *}$ & $.414^{* *}$ & $.411^{* *}$ & - & .000 & -.046 \\
\hline 10. AUC $_{g}$ & 350.34 & 119.78 & -.12 & $-.289^{*}$ & -.167 & -.037 & -.061 & -.241 & -.148 & -.195 & -.151 & - & -.112 \\
\hline 11. $\mathrm{AUC}_{1}$ & 57.98 & 78.66 & -.10 & -.145 & -.020 & $.276^{*}$ & .096 & -.169 & -.081 & .026 & .081 & $.263^{*}$ & - \\
\hline
\end{tabular}

Note. Within day correlations are shown in the upper triangle. Active $=1$ Non-active $=0 . \mathrm{AUC}_{\mathrm{g}}=$ Area under the curve with respect to total cortisol output, $\mathrm{AUC}_{1}=$ Area under the curve with respect to cortisol awakening response.

** Correlation is significant at the 0.01 level (2-tailed).

* Correlation is significant at the 0.05 level (2-tailed). 


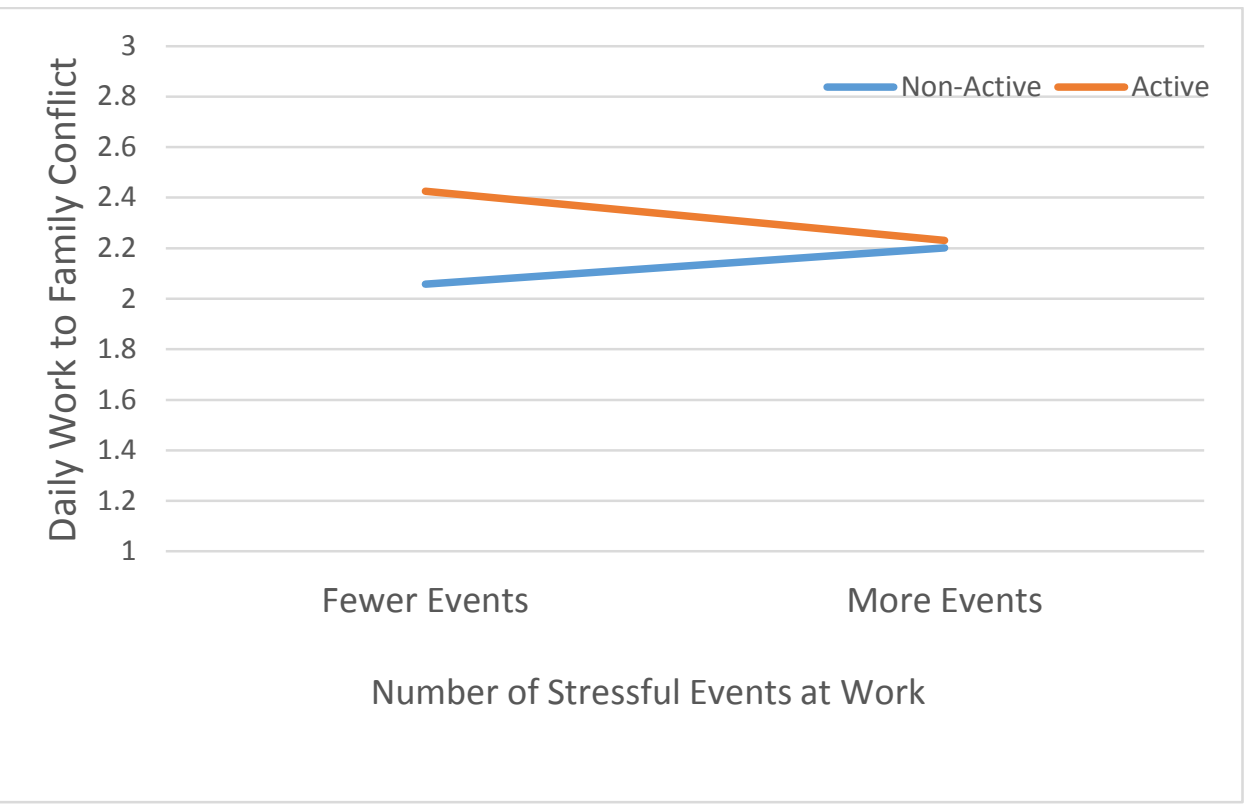

Figure 2. Cross-level interaction of commute mode by stressful life events 


\subsection{DISCUSSION AND CONCLUSIONS}

The results suggest that active commuting benefits individuals through associations to lower job stress, life stress, family-to-work conflict and work-to-family conflict, and lower cortisol volume with respect to change in the cortisol awakening response. However, these results were marginally significant for family-to-work conflict and job stress. Nevertheless, the results imply that those choosing active commute modes may benefit their well-being, and that employers may have an interest in promoting these commuting behaviors. Marginally significant results and lack of significant findings for daily fluctuations of focal phenomena underscore some limitations of our study. It may be that active commuting influences individuals' daily wellbeing and work behavior in a way that the present research lacked the statistical power to detect or the design to understand. Future research should seek to expand the set of variables to other work factors such as work engagement or interactions with coworkers to assess the influence that mode choice exerts over commuters' daily work behaviors. Similarly, future research should test the processes and contingency factors underlying the associations between focal phenomena, which might reveal how active commuting influences daily fluctuations in well-being and behavior.

\subsection{OVERALL DISCUSSION}

The most long-lasting potential impact of this research is that it brings a holistic view of individual resource allocation between work roles, non-work (including family) roles, and commuting into travel behavior research. Current transportation research rarely takes work stress and non-work demands into consideration while predicting travel behavior; this research attempts to fill the gap by acknowledging the key role that life stress (work and non-work) may play in daily commute decision making. This research used both firsthand data collected via daily diary design and existing, large-sample, national travel survey data. This design allowed us to make strong conclusions regarding our research questions because it ensured both internal and external validity by capturing day-to-day dynamics in resources allocation and daily influence of active commuting on commuting workers' health and work outcomes, and taking advantage of a large, representative sample in producing findings generalizable to larger populations.

The results carry a few, notable, theoretical and practical implications. Theoretically, the interactions between commute, work, and family domains shed light on how these domains may influence each other during mode choices. In so doing, we cast new questions relative to the current, dominant, mode-choice models that include subjective criteria such as family characteristics (e.g., Stern \& Richardson, 2005). That these choices carry significant impact on work and well-being outcomes further highlight the need to understand how commute decisions influence people's daily lives. Although a paucity of research exists comparing mode choices relative to work, family, and well-being outcomes, the results from our Studies 1 and 2 underscore the need for more research that investigates mode choice from a criteria perspective. More than that, although a comparative MNL model was not feasible in the current study, the apparent differences in mode share and correlations between focal variables across the overall population and the low-SES population in Study 1 suggest that mode-choice models should make affordances for the economic considerations inherent in commute mode choices. Beyond its influence on mode choice, SES may influence other effects of mode choice, such as well- 
being, work outcomes, and active commute promotions. More research is needed to uncover these potential influences.

Findings from this proposed study also have important implications for workers, employers, and stakeholders such as transportation agencies and planners. Specifically, workers who have access to more than one commute mode may be able to make more informed decisions from learning about our study findings - that is, the health, safety, and work performance implications of different modes and how their state of stress from different life roles may influence their decision on commute mode. Further, upon learning about our study findings, employers can be more motivated to devise organizational policies (e.g., offer on-site childcare, allow flexible work schedules, promote proactive commute cultures, provide bike racks, etc) in efforts to help workers manage multiple life roles (e.g., work, family, school, volunteering). Such efforts will ultimately facilitate workers' choice of commute modes with better outcomes for their health, safety, and productivity, and better outcomes for organizations' bottom line and cost management related to employee health and retention. Finally, our research findings will inform transportation agencies, planners, and advocacy groups. For transportation agencies and planners, providing less-stressful commute options with capacity to help workers manage multiple life roles (e.g., having frequent public transit lines with stops at childcare facilities) may be viable strategies to facilitate usage of commute modes that benefit the performance and safety of the transportation system. For advocacy groups (including local agencies such as Bicycle Transportation Alliance and BikePortland.org), study results will inform policy recommendations, impact strategies for recruiting new bicycle commuters, and help determine the best recommendations for planning safe and low-stress bicycle routes. 


\section{REFERENCES}

Ben-Akiva, M. E., \& Lerman, S. R. (1985). Discrete choice analysis: theory and application to travel demand (Vol. 9). MIT press.

Berglund, E., Lytsy, P., \& Westerling, R. (2016). Active traveling and its associations with selfrated health, BMI and physical activity: A comparative study in the adult swedish population. International journal of environmental research and public health, 13(5), 455.

Blanch, A., Aluga, A. (2012). Social support (family and supervisor), work-family conflict, and burnout: Sex differences. Human Relations, 65, 811-833.

Bopp, M., Gayah, V. V., \& Campbell, M. E. (2015). Examining the link between public transit use and active commuting. International journal of environmental research and public health, 12(4), 4256-4274.

Bopp, M., Kaczynski, A. T., \& Campbell, M. E. (2013). Health-related factors associated with mode of travel to work. Journal of environmental and public health, 2013.

Broach, J. P. (2016). Travel mode choice framework incorporating realistic bike and walk routes (Unpublished doctoral dissertation). Portland State University, Portland, OR.

Bureau of Labor Statistics (2010). American time-use survey. Retrieved from http://www.bls.gov/tus/

Bureau of Labor Statistics (2012). American time-use survey. Retrieved from http://www.bls.gov/tus/

Bureau of Labor Statistics (2013). American time-use survey. Retrieved from http://www.bls.gov/tus/

Busemeyer, J. R., \& Townsend, J. T. (1993). Decision field theory: A dynamic-cognitive approach to decision making in an uncertain environment. Psychological review, 100(3), 432.

Centers for Disease Control. 2011a. Health, United States. Retrieved May 17, 2012 fromhttp://www.cdc.gov/nchs/fastats/exercise.htm

Centers for Disease Control. 2011b. Overcoming Barriers to Physical Activity. Retrieved May 17, 2012 from http://www.cdc.gov/physicalactivity/everyone/getactive/barriers.html

Chen, C., Gong, H., \& Paaswell, R. (2008). Role of the built environment on mode choice decisions: additional evidence on the impact of density. Transportation, 35(3), 285-299. 
Clark, B., Chatterjee, K., \& Melia, S. (2016). Changes to commute mode: The role of life events, spatial context and environmental attitude. Transportation Research Part A: Policy and Practice, 89, 89-105.

Chu, Z., Cheng, L., \& Chen, H. (2012, August). A review of activity-based travel demand modeling. In CICTP: Multimodal Transportation Systems-Convenient, Safe, CostEffective, Efficient. ASCE.

Collins, C. M., \& Chambers, S. M. (2005). Psychological and situational influences on commuter-transport-mode choice. Environment and behavior, 37(5), 640-661.

Dunn, A.L., Trivedi, M.H., Kampert, J.B., Clark, C.G., and Chambliss, H.O. 2005. The DOSE study: a clinical trial to examine efficacy and dose response of exercise as treatment for depression. Controlled Clinical Trials, 23(5), 584-603.

Evans, G. W., \& Wener, R. E. (2006). Rail commuting duration and passenger stress. Health Psychology, 25(3), 408.

Faulk, D., \& Hicks, M. J. (2016). The impact of bus transit on employee turnover: Evidence from quasi-experimental samples. Urban Studies, 53(9), 1836-1852.

Gilboa et al., (2008). A meta-analysis of work demand stressors and job performance: Examining main and moderating effects. Personnel Psychology, 61, 227-271.

Hammer, L.B., Cullen, J.C., Neal, M.B., Sinclair, R.R., Shafiro, M.V. (2005). The longitudinal effects of work-family conflict and positive spillover on depressive symptoms among dual-earner couples. Journal of occupational health psychology, 10, 138-154.

Heinen, E., Maat, K., \& Van Wee, B. (2011). Day-to-day choice to commute or not by bicycle. Transportation Research Record: Journal of the Transportation Research Board, (2230), 9-18.

Heinen, E., Maat, K., \& van Wee, B. (2013). The effect of work-related factors on the bicycle commute mode choice in the Netherlands. Transportation, 40(1), 23-43.

Hobfoll, S. E. (1989). Conservation of resources: A new attempt at conceptualizing stress. American psychologist, 44(3), 513.

Hu, P.S., \& Reuscher, T.R. 2004. Summary of travel trends: 2001 National Household Travel Survey. Washington (DC): US Department of Transportation, Federal Highway Administration. Retrieved May 21, 2012 from nhts.ornl.gov/2001/pub/STT.pdf

Kaczynski, A. T., Bopp, M. J., \& Wittman, P. (2012). To drive or not to drive: factors differentiating active versus non-active commuters. Journal of Health Behavior and Public Health, 2(2), 14-19. 
Karasek, R., \& Theorell, T. 1990. Healthy Work. New York, NY: Basic Books.

Koppelman, Frank S., and Chandra Bhat. 2006. A Self Instructing Course in Mode Choice Modeling: Multinomial and Nested Logit Models. FTA.

Kouvonen, A., Kivimiki, M., Elovainio, M., Virtanen, M., Linna, A., \& Vahtera, J. 2005. Job strain and leisure-time physical activity in female and male public sector employees. Preventive Medicine, 41, 532-539.

Koslowsky, M., \& Krausz, M. 1993. On the relationship between commuting, stress symptoms, and attitudinal measures: A LISREL application. Journal of Applied Behavioral Science, 29, 485-492.

Li, Q., Ooeda, Y., Matsunaga, C., \& Sumi, T. (2002). Identifying the Determinants of Commuting Travel Mode Choice from Daily Commutation Behavior. Memoirs of the Faculty of Engineering, Kyushu University 62, 191-206.

McFadden, D. (1974). The measurement of urban travel demand. Journal of public economics, 3(4), 303-328.

Morris, N., Clayton, D.G., \& Everitt, M.G. 1990. Exercise in leisure-time: Coronary attack and death rates. British Heart Journal, 63, 325-334.

Novaco, R.W., Stokols, D., \& Milanesi, L. (1990). Objective and Subjective Dimensions of Travel Impedance as Determinants of Commuting Stress. Am. J. of Community Psychology 18, 231-257.

Oliveira, R., Moura, K., Viana, J., Tigre, R., \& Sampaio, B. (2015). Commute duration and health: Empirical evidence from Brazil. Transportation Research Part A: Policy and Practice, 80, 62-75.

Rimmele, U. Zellweger BC, Marti B, Seiler R, Mohiyeddini C, Ehlert U, Heinrichs M. (2007). Trained men show lower cortisol, heart rate, and psychological responses to psychosocial stress compared with untrained men. Psychoneuroendocrinology, 32, 627-635.

Robinson, A. 1991. Lung cancer, the motor vehicle, and its subtle influence on bodily functions. Medical Hypotheses, 28, 39-43.

Scheiner, J., \& Holz-Rau, C. (2007). Travel mode choice: affected by objective or subjective determinants? Transportation, 34(4), 487-511.

Smith, O. B. (2013). Peak of the Day or the Daily Grind: Commuting and Subjective Well-Being. Unpublished dissertation, Portland State University, Portland, Oregon.

Stern, Eliahu, and Harry W. Richardson. 2005. "Behavioural Modelling of Road Users: Current Research and Future Needs.” Transport Reviews 25 (2): 159-180. 
The US Department of Health \& Human Services (2017). 2017 POVERTY GUIDELINES FOR THE 48 CONTIGUOUS STATES AND THE DISTRICT OF COLUMBIA. Retrieved from ttps://aspe.hhs.gov/poverty-guidelines

U.S. Census Bureau (2014). American community survey. Retrieved from https://www.census.gov/programs-surveys/acs/.

Wener, R.E., \& Evans, G.W. (2011). Comparing Stress of Car and Train Commuters. Transportation Research Part F: Traffic Psychology and Behaviour, 14, 111-116.

Yang, L.-Q., Spector, P.E., Sanchez, J.I. ... Woo, J-M. (2012). Individualism-collectivism as a moderator of the work demands-strains relationship: A cross-level and cross-national examination. Journal of International Business Studies, 43, 424-443. 


\subsection{APPENDICES}

Appendix 1

Study1: Descriptive statistics for variables included in analyses

\begin{tabular}{|c|c|c|c|c|c|c|c|c|c|c|c|c|c|c|c|c|c|c|c|c|c|c|c|c|}
\hline Variables & $M$ & $S D$ & 1 & 2 & 3 & 4 & 5 & 6 & 7 & 8 & 9 & 10 & 11 & 12 & 13 & 14 & 15 & 16 & 17 & 18 & 19 & 20 & 21 & 22 \\
\hline \multicolumn{25}{|l|}{ Demographics } \\
\hline 1. Female ${ }^{\mathrm{a}}$ & .47 & .50 & & & & & & & & & & & & & & & & & & & & & & \\
\hline 2. House income ${ }^{\mathrm{d}}$ & 3.04 & 2.25 & .00 & & & & & & & & & & & & & & & & & & & & & \\
\hline 3. Age & 44.8 & 13.1 & .05 & .25 & & & & & & & & & & & & & & & & & & & & \\
\hline 4. Student ${ }^{\mathrm{a}}$ & .05 & .23 & .05 & $\overline{-.05}$ & $\underline{-.29}$ & & & & & & & & & & & & & & & & & & & \\
\hline 5. College ${ }^{a}$ & .68 & .47 & .06 & .28 & .00 & .05 & & & & & & & & & & & & & & & & & & \\
\hline 6. Caucasian ${ }^{\mathrm{b}}$ & .83 & .38 & $\overline{-.04}$ & $\overline{.04}$ & .02 & $-\overline{-.02}$ & -.02 & & & & & & & & & & & & & & & & & \\
\hline 7. Black $^{\mathrm{b}}$ & .11 & .32 & .06 & -.03 & .02 & .03 & -.02 & $\underline{. .77}$ & & & & & & & & & & & & & & & & \\
\hline 8. Hispanic ${ }^{\mathrm{b}}$ & .13 & .34 & -.05 & $\underline{-.15}$ & -.10 & .00 & $\underline{-.26}$ & .13 & -.11 & & & & & & & & & & & & & & & \\
\hline \multicolumn{25}{|l|}{ Work Demands } \\
\hline 9. Job change $\mathrm{J}^{\mathrm{a}}$ & .03 & .16 & .02 & .01 & .01 & .02 & .02 & -.01 & .00 & .02 & & & & & & & & & & & & & & \\
\hline 10. Full-time work ${ }^{\mathrm{a}}$ & .82 & .38 & $\underline{-.19}$ & .16 & -.02 & $\underline{-.11}$ & .10 & .01 & -.02 & -.01 & .01 & & & & & & & & & & & & & \\
\hline 11. Work hours ${ }^{\mathrm{C}}$ & 8.17 & 2.44 & $\overline{-.09}$ & .13 & -.02 &. .05 & .07 & .01 & -.01 & -.03 & .00 & .35 & & & & & & & & & & & & \\
\hline 12. Multiple jobs ${ }^{\mathrm{a}}$ & .11 & .31 & $\overline{.02}$ & $\overline{-.01}$ & .01 & .02 & .05 & .03 & .01 & -.04 & .00 & .05 & .01 & & & & & & & & & & & \\
\hline \multicolumn{25}{|l|}{ Family Demands } \\
\hline 13. Cohabitation ${ }^{\mathrm{a}}$ & .59 & .49 & $\underline{-.12}$ & $\underline{.13}$ & .04 & $\underline{-.13}$ & .08 & .12 & $\underline{-.18}$ & $\underline{.05}$ & .00 & .11 & .07 & -.01 & & & & & & & & & & \\
\hline 14. Spouse works ${ }^{a}$ & .42 & .49 & -.01 & -.03 & -.01 & -.07 & .11 & .10 &. .12 &. .07 & .00 & .06 & .04 & .02 & .71 & & & & & & & & & \\
\hline 15. Child count & .88 & 1.13 & -.05 & -.37 & $\underline{-.35}$ & .06 &. .07 & .03 &. .08 & .08 & -.01 & $-\overline{-.02}$ & $-\overline{-.02}$ & .00 & .30 & .20 & & & & & & & & \\
\hline 16. Child age (avg) & 5.77 & 8.01 & .07 & -.22 & .13 & .09 &. .05 & -.01 & -.03 & .07 & .01 & .01 & .01 & .00 & .22 & .15 & .26 & & & & & & & \\
\hline 17. Childcare hrs ${ }^{\mathrm{c}}$ & 1.11 & 2.19 & .07 & $\overline{-.21}$ &. .20 & $\overline{.02}$ & $\overline{.01}$ & .04 & $\underline{.06}$ & $\overline{.03}$ & -.01 & -.05 & $\underline{.15}$ & -.02 & .21 & .17 &.$\overline{.46}$ & .10 & & & & & & \\
\hline 18. Adult-care ${ }^{\mathrm{ac}}$ & .06 & .25 & .01 & $\overline{-.02}$ & $\overline{.03}$ & -.02 & -.02 & -.02 & .03 & -.03 & .04 & .01 & $\overline{-.03}$ & .00 & .05 & .05 & .00 & $\overline{.04}$ & .01 & & & & & \\
\hline 19. Homecare hrs ${ }^{\mathrm{c}}$ & 1.10 & 1.29 & .21 & -.02 & .14 & -.06 & -.05 & .05 & $\underline{.06}$ & .04 & -.01 & $\underline{-.13}$ & -.31 & .01 & .02 & .06 & .00 & .10 & .08 & .00 & & & & \\
\hline \multicolumn{25}{|l|}{ Commute Demand } \\
\hline 20. Commute hrs ${ }^{\mathrm{c}}$ & .77 & .61 & $\underline{-.11}$ & .03 & .02 & -.04 & .03 & -.02 & .02 & .02 & .00 & .07 & .02 & -.01 & .08 & .03 & .01 & .00 & -.05 & -.01 & $\underline{-.08}$ & & & \\
\hline \multicolumn{25}{|l|}{ Commute Modes } \\
\hline 21. Auto bc & .95 & .22 & .05 & .00 & .04 & .01 & .02 & .06 & -.07 & -.04 & -.05 & .03 & .03 & .02 & .08 & .06 & .04 & .08 & .03 & .03 & .02 & $\underline{-.11}$ & & \\
\hline 22. Transit ${ }^{\mathrm{bc}}$ & .02 & .15 & $\overline{-.04}$ & .02 & -.05 & -.03 & .03 &.$\overline{-.09}$ & .09 & .03 & .01 & .00 & .00 & -.04 & $\overline{-.04}$ & $\overline{-.04}$ & -.03 & $\overline{-.06}$ & -.04 & -.02 & -.04 & .22 & $\underline{-.69}$ & \\
\hline 23. Active ${ }^{\mathrm{bc}}$ & .03 & .16 & -.04 & -.02 & .00 & .01 & -.05 & .01 & .00 & .02 & .06 & -.04 & -.05 & .01 & $\underline{-.07}$ & -.04 & -.02 & -.05 & .01 & -.01 & .01 &.$\overline{.06}$ &. .71 & -.03 \\
\hline
\end{tabular}

Note. Bold $=p<.05$, Bold $=p<.01$, activity variables. Estimators and state dummies are excluded. Commute mode dummies illustrate correlations independent of modelling. $\mathrm{M}=$ mean; $\mathrm{SD}=$ standard deviation .

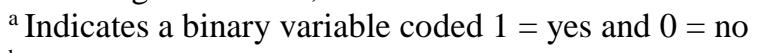

b Indicates a dummy variable

${ }^{\mathrm{c}}$ Indicates an activity variable measured on the diary day

${ }^{\mathrm{d}}$ Variable is normalized by household size in units of \$10,000 per household member 


\section{Appendix 2}

Study 1: Subgroup (low SES) descriptive statistics for focal variables

\begin{tabular}{|c|c|c|c|c|c|c|c|c|c|c|c|c|c|c|c|c|c|c|c|c|c|c|c|c|}
\hline Variables & $M$ & $S D$ & 1 & 2 & 3 & 4 & 5 & 6 & 7 & 8 & 9 & 10 & 11 & 12 & 13 & 14 & 15 & 16 & 17 & 18 & 19 & 20 & 21 & 22 \\
\hline \multicolumn{25}{|l|}{ Demographics } \\
\hline 1. Female ${ }^{\mathrm{a}}$ & .46 & .50 & & & & & & & & & & & & & & & & & & & & & & \\
\hline 2. House income $\mathrm{d}^{\mathrm{d}}$ & 3.37 & 1.48 & .11 & & & & & & & & & & & & & & & & & & & & & \\
\hline 3. Age & 47.5 & 14.9 & .31 & .17 & & & & & & & & & & & & & & & & & & & & \\
\hline 4. Student ${ }^{\mathrm{a}}$ & .17 & .38 & .11 & -.18 & -.43 & & & & & & & & & & & & & & & & & & & \\
\hline 5. College ${ }^{\mathrm{a}}$ & .51 & .50 & -.10 & .07 & $\overline{-.28}$ & .16 & & & & & & & & & & & & & & & & & & \\
\hline 6. Caucasian ${ }^{\mathrm{b}}$ & .65 & .48 & .03 & -.04 & .09 & -.02 & -.01 & & & & & & & & & & & & & & & & & \\
\hline 7. Black ${ }^{\mathrm{b}}$ & .32 & .47 & .02 & .05 & -.06 & -.00 & -.02 & -.94 & & & & & & & & & & & & & & & & \\
\hline 8. Hispanic ${ }^{b}$ & .13 & .34 & -.11 & .07 & -.03 & -.10 & $\underline{-.21}$ & .19 & -.17 & & & & & & & & & & & & & & & \\
\hline \multicolumn{25}{|l|}{ Work Demands } \\
\hline 9. Job change ${ }^{a}$ & .01 & .12 & .01 & -.12 & -.05 & -.08 & -.00 & -.04 & .05 & -.04 & & & & & & & & & & & & & & \\
\hline 10. Full-time work ${ }^{\mathrm{a}}$ & .58 & .49 & -.15 & -.07 & $\underline{-.22}$ & -.10 & .00 & -.01 & .01 & -.07 & -.02 & & & & & & & & & & & & & \\
\hline 11. Work hours ${ }^{\mathrm{C}}$ & 7.29 & 2.83 & -.16 & -.02 & $\overline{-.19}$ & -.06 & .00 & -.12 & .11 & -.01 & -.01 & .40 & & & & & & & & & & & & \\
\hline 12. Multiple jobs ${ }^{\mathrm{a}}$ & .11 & .32 & .02 & -.07 & .01 & .06 & .04 & -.02 & -.03 & -.03 & -.05 & .24 & .11 & & & & & & & & & & & \\
\hline \multicolumn{25}{|l|}{ Family Demands } \\
\hline 13. Cohabitation ${ }^{\mathrm{a}}$ & .00 & .00 & - & - & - & - & - & - & - & - & - & - & - & - & & & & & & & & & & \\
\hline 14. Spouse works ${ }^{\mathrm{a}}$ & .00 & .00 & - & - & - & - & - & - & - & - & - & - & - & - & - & & & & & & & & & \\
\hline 15. Child count & .00 & .00 & - & - & - & - & - & - & - & - & - & - & - & - & - & - & & & & & & & & \\
\hline 16. Child age (avg) & 10.7 & 5.71 & .07 & -.15 & .85 & - & -.49 & -.27 & .36 & .24 & -.62 & -.09 & .42 & .25 & - & - & - & & & & & & & \\
\hline 17. Childcare hrs ${ }^{\mathrm{c}}$ & .20 & 1.25 & .06 & .03 & $\overline{.06}$ & -.07 & -.02 & .01 & -.01 & -.05 & -.02 & .06 & -.06 & .09 & - & - & - & .00 & & & & & & \\
\hline 18. Adult-care ${ }^{\mathrm{ac}}$ & .08 & .27 & -.11 & -.10 & -.00 & .02 & -.09 & .01 & .01 & -.11 & -.03 & .05 & -.15 & .08 & - & - & - & .04 & .25 & & & & & \\
\hline 19. Homecare $\mathrm{hrs}^{\mathrm{c}}$ & .80 & 1.11 & .21 & -.01 & .25 & -.08 & .02 & .20 &. .19 & .03 & -.08 & -.14 & -.34 & .03 & - & - & - & .02 & .21 & .03 & & & & \\
\hline Commute Demand & & & & & & & & & & & & & & & - & - & - & & & & & & & \\
\hline 20. Commute hrs ${ }^{\mathrm{c}}$ & .79 & .63 & -.13 & .12 & .06 & -.13 & .07 & .04 & -.06 & .24 & -.12 & .09 & .07 & .04 & - & - & - & .06 & -.14 & -.01 & -.12 & & & \\
\hline Commute Modes & & & & & & & & & & & & & & & - & - & - & & & & & & & \\
\hline 21. Auto ${ }^{\mathrm{bc}}$ & .84 & .36 & .02 & -.03 & .05 & .07 & .10 & .20 & -.22 & -.09 & .05 & .04 & .05 & .11 & - & - & - & -.06 & -.07 & .07 & .05 &. .29 & & \\
\hline 22. Transit ${ }^{\mathrm{bc}}$ & .09 & .29 & .03 & .11 & -.00 & -.06 & -.01 & -.14 & .16 & .09 & -.04 & .02 & -.02 & -.12 & - & - & - & .11 & -.39 & -.03 & -.08 & .42 & -.75 & \\
\hline 23. Active ${ }^{b c}$ & .06 & .24 & -.06 & -.09 & -.07 & -.04 & -.14 & -13 & .14 & .03 & -.03 & -.08 & -.04 & -.02 & - & - & - & -.04 & .37 & -.08 & .02 & -.07 & -.60 & -.09 \\
\hline \multicolumn{25}{|c|}{$\begin{array}{l}\text { Note. Bold }=p<.05, \underline{\text { Bold }}=p<.01 \text {, activity variables. } \\
\text { modelling. } \mathrm{M}=\text { mean; } \mathrm{SD}=\text { standard deviation. } \\
\text { a Indicates a binary variable coded } 1=\text { yes and } 0=\text { no } \\
\text { b Indicates a dummy variable } \\
{ }^{\mathrm{c}} \text { Indicates an activity variable measured on the diary da }\end{array}$} \\
\hline
\end{tabular}


Transportation Research and Education Center

Portland State University

1900 S.W. Fourth Ave., Suite 175

Portland, OR 97201 